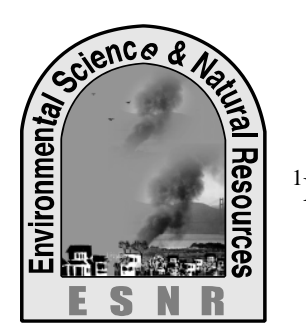

\title{
Climatic Effects on Food Security in Bangladesh
}

\author{
K. M. H. Kabir ${ }^{*}$ and M. K. Uddin ${ }^{2}$ \\ ${ }^{1}$ Renewable Energy Project, Power Division, Dhaka-1215, Bangladesh, \\ ${ }^{1}$ Department of Environmental Sciences, Jahangirnagar University, Savar, Dhaka-1342, Bangladesh \\ *Corresponding author: as.kabir@gmail.com
}

\begin{abstract}
Impacts of sea level rise in Bangladesh were assessed using data from secondary sources. The review study reveals that one meter sea level rise will affect the vast coastal areas and flood plain zone of Bangladesh. Both livelihood options of coastal communities and the natural environment of the coastal areas will be affected by the anticipated sea level rise, which will also affect food security of the country. The ecosystem of the Sundarban mangrove forest will be totally lost with one meter rise in sea level. An integrated combined effort of Bangladesh Government, local people and International communities and stakeholders are indispensable for the survival of the coastal communities and ecosystem of southern areas of Bangladesh.
\end{abstract}

Key words: Food security, Impacts and Sea level rise

\section{Introduction}

Crop production has enormously increased through the advancement in plant science and agricultural activities but globally concern climate change may have significant effects on food chain and food supply resulting on stressed food security in Bangladesh. Gradual invasion in agricultural land, unplanned urbanization, industrialization, over exploitation of natural resources including mining, manmade dams and infrastructures including global warming are ultimately changing the climate that reflects on downward crop production. Many international organizations are working to mitigate and adoption of climatic resilience that includes Food and Agriculture Organization (FAO), Columbia Center for International Earth Science Information Network (CIESIN) and Intergovernmental Panel on Climate Change (IPCC).

During early 1990's United States Environmental Protection Agency (US EPA) sponsored a study through involving agricultural scientists in 18 countries estimated potential changes in crop yields using crop models and the Global Circulation/Climate Model (GCM) scenarios at 112 sites (Rosenzweig and Parry, 1994). From the above study it appears that, the developing countries in lower latitudes will bear the burden of these climatic dilemmas. Changed weather patterns will increase vulnerabilities of crop production through microbial infestation, pathogenic infection, pest and unpleasant weed infestations. These extreme tainted weather events will affect both developed and developing countries. In this regard the developed countries have more resources to deal with vulnerabilities and developing countries would be facing worst situation in future.

Since 1961 the global sea level has risen at an average rate of $1.8 \mathrm{~mm} \mathrm{yr}^{-1}$ subsequently since 1993 at 3.1 $\mathrm{mm} / \mathrm{yr}$, with contributions from thermal expansion, melting glaciers and ice caps and the polar ice sheets. From 1900 to 2005, precipitation increased significantly in eastern parts of North and South America, northern Europe and northern and central Asia but declined in the Sahel, the Mediterranean, southern Africa and parts of southern Asia. Globally, the area affected by drought has increased since the 1970s. Global Green House Gas (GHG) emissions due to human activities have grown since pre-industrial times, with an increase of $70 \%$ between 1970 and 2004. The Inter-Governmental Panel on Climate Change (IPCC) Special Report on Emission Scenarios (IPCC SRES, 2000) projects an increase of global GHG emissions by $25-90 \%\left(\mathrm{CO}_{2}\right.$-eq) between 2000 and 2030.

There is also high confidence that many semi-arid areas (e.g. Mediterranean basin, western United States, southern Africa and northeast Brazil and Bangladesh) will suffer a decrease in water resources due to climate change which ultimately are of great concern for food security in this deltaic region. This paper has focused on sea level rise (SLR), drought, saline intrusion and food security and subsequent mitigation and subsequent recommendations.

Information was collected from 20 respondents' including 02 FGD's using structured checklists. Excel spread sheet has been used to store and use collected data. The collected data has been grouped and analyzed using statistical packages e.g. SPSS, excel, past etc., for different analyses as required to present in this paper. The data has been validated, grouped and analyzed through using SPSS, Excel and PAST statistical packages where applicable.

\section{Limitations}

The climatic data (weather data) are usually take a long period, which restricts to get up front primary data in this regard. Published agricultural data which were generated by Department of Agricultural Extension (DAE) and other agricultural organizations in Bangladesh which were used in this paper.

\section{Results and Discussion}

Current cereal crop production in 2014 has been analyzed in different ways and found to be regression values as $\mathrm{R}^{2}=1$ with present crop production equation, $\mathrm{Y}=117.0 \mathrm{x}-$ 93.78. The subsequent available agricultural land has also been analyzed and found to be as following relation $\mathrm{Y}=4.405 \mathrm{x}+31.49, \mathrm{R}^{2}=0.155$. In the recent time the agricultural land is gradually decreasing at an annual average rate of $0.5 \%$ between 
1985-86 and 2006-07 and the net cropped area decreased by $11 \%$ (BBS, 2005, 2009) in Bangladesh and at times there could be a shortage of agricultural land to feed the millions in Bangladesh. In earlier year 2013 the rice crop production was $338.3 \mathrm{~m}$ ton and subsequently wheat and maize were $12.55 \mathrm{~m}$ ton and $0.91 \mathrm{~m}$ ton. The targeted crop production and achievement is graphed in the following Fig. 1, where the production gap is gradually increasing with the decreasing of the land area in Bangladesh (DAE, 2014).

In recent time scientists around the world expressed their concern that due to climatic variations the USA and other advanced countries may face serious drought condition including the neighboring India from where we import large amount of cereal grains and other essential crops including fishes.

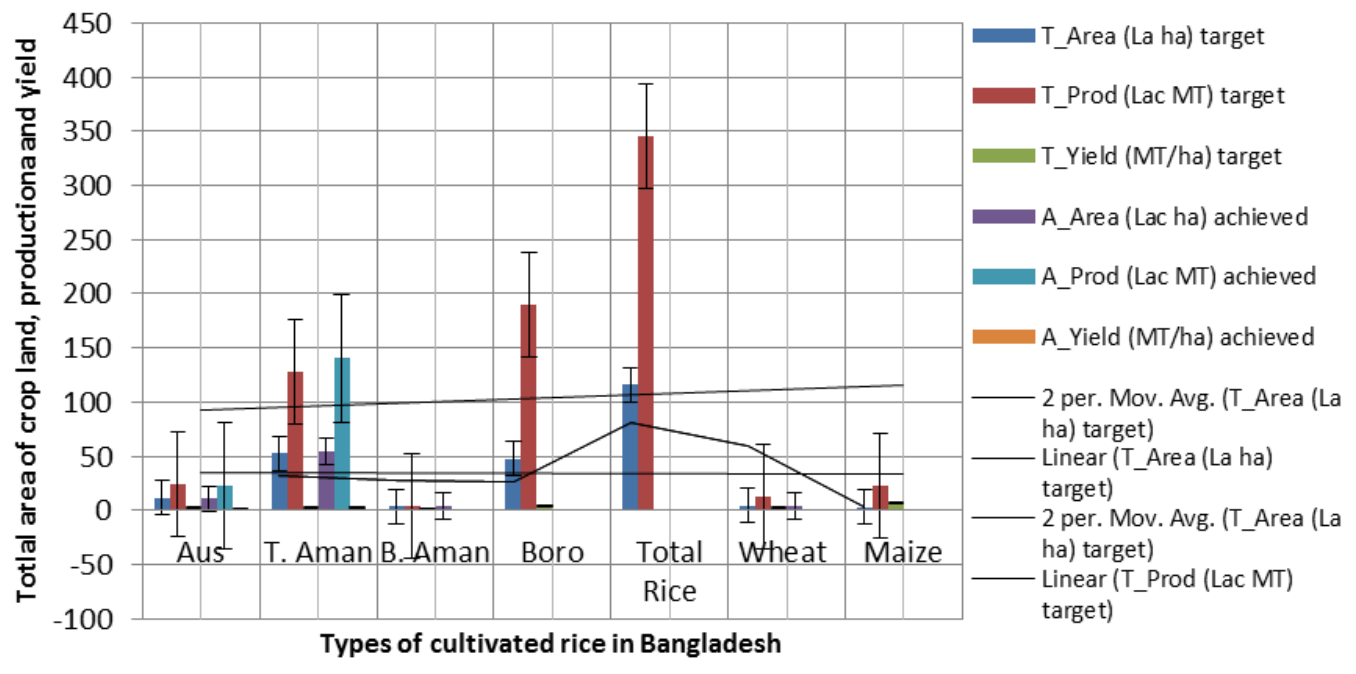

Fig. 1. The target and achievement of cereal crop production scenario in 2014 as projected using error bar with standard error

The same trends are conspicuous for other crops namely; oil seed, winter and summer vegetables, spices crops etc.

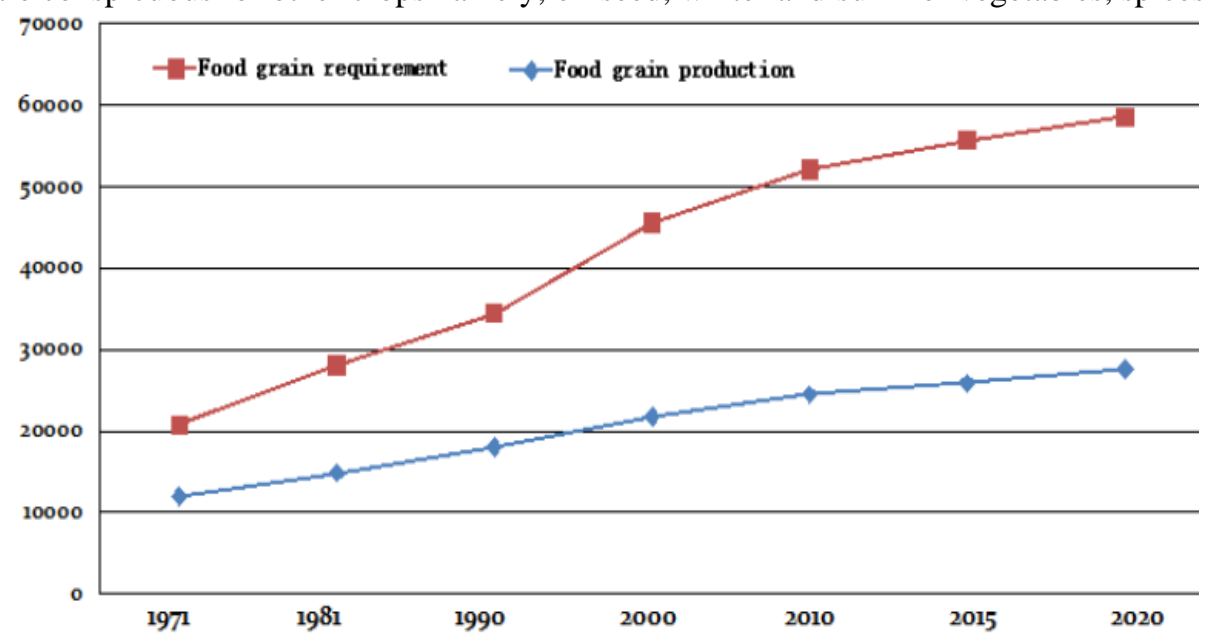

Fig. 2. Food Grain requirement \& expected production up to 2020 in Bangladesh.

Fisheries and livestock sub-sector is very crucial for the economic development and food security in Bangladesh. Livestock and fisheries together contribute $3.3 \%$ of the GDP and $10.33 \%$ of the agriculture sector and provide daily dietary protein and milk requirements of the people.

With annual population growth of 1.8 million people, Bangladesh requires approximately an additional 300,000 metric tons of rice per year (Grain and Feed Annual Bangladesh, 2013). With growing population, planning for future cereal production to meet food security challenges would require projections of future supply and demand for cereals. Pulses are vital components in diversification of Bangladesh's predominantly rice-based cropping system. Average 550,000 tons of pulses are produced in Bangladesh every year. Lentil is the second most important pulse crop in terms of area $(154,000 \mathrm{ha})$ and production $(116,000 \mathrm{t})$, but ranks the highest in consumer preference and total consumption (BBS, 2002). In Fig. 2 food grain production and requirement in Bangladesh has been depicted to understand the food security as a whole (BBS, 2010). 
The salinity problem in southwestern region of Bangladesh has not been acknowledged properly, in recent past observations, it was perceived that due to increasing degree of salinity and expansion of affected areas the agricultural land use practices are becoming restricted (Karim et al., 1990). In this regard the crop yields, cropping intensity, production levels are being decreased with comparison to other part of the country (Rahman and Ahsan, 2001). The total affected area by saline intrusion has increased to about 0.1056 million hectares from 0.833 million hectares in the last four decades. In 2001, the size of the salinity-affected land was nearly 0.1020 million hectares and the severely saline affected area are reported to be in Khulna, Bagerhat, Satkhira and Patuakhali districts (SRDI, 2010).

\section{Climate change effects in Asian countries}

With improved calculation models tacit relationship between climate change and food security has been found including irreversible climate change and its impacts on food production. The unprecedented impacts of climate change along with other environmental and geomorphologic changes make more concerns over food security especially, for the poor and marginal population (Gregory and Ingram, 2000; Parry et al., 2001). Freshwater availability in large river basins around Central, South, East and South-East Asia has been projected to be decreased by 2050 . The coastal regions having heavily-populated mega-delta regions in South, East and South-East Asia, will be at greatest risk due to increased flooding from the sea including flooding from rivers in some mega-deltas. The rapid urbanization, industrialization and economic development will force environment and natural resources to a limiting factor, floods and droughts are expected to rise in East, South and South-East Asia resulting in a stressful food production.

According to the IPCC report the South Asian region e.g. Bangladesh, Bhutan, India, Myanmar, Nepal, Pakistan, Sri Lanka and the Tibetan Plateau have large climate variability along with human activities. Between 1985 and 1998 the temperature in the month of May has risen by $1^{\circ} \mathrm{C}$ and by $0.5^{\circ} \mathrm{C}$ in November.
Decadal precipitation has been recorded above the long term average since the 1960s (IPCC, 2001 and 2007).

\section{Apparent Climate change effects in Bangladesh context}

Bangladesh is highly vulnerable to the projected impacts of climate change, as these are likely to increase the already high risk of disasters, and exacerbate existing vulnerabilities. Global warming will cause changes such as higher temperatures, sea level rise and changing rainfall patterns, as well as more abrupt effects, such as an increase in the intensity and frequency of extreme events such as floods, storm surges and cyclones.

An increase of one degree centigrade in ocean temperature could increase tropical cyclone intensity by as much as $10 \%$. At the same time, some areas of the country may be at greater risk of drought and food insecurity during the dry season and agricultural productivity in coastal areas are reported to be affected by increasing salinity. In this regard Ahmed and Alam, (1999) reported that, the average increase in temperature in Bangladesh would be $1.3^{\circ} \mathrm{C}$ and $2.6^{\circ} \mathrm{C}$ by the year 2030 and 2075 respectively with respect to the base year 1990. The seasonal variation of temperature will be more in winter than in summer: $1.3^{0}$ $\mathrm{C}$ in winter and $0.7^{0} \mathrm{C}$ in summer for 2030 and $2.1^{\circ} \mathrm{C}$ for winter and $1.7^{0} \mathrm{C}$ for summer for 2075. Karmakar and Shrestha (2000), using the 1961-1990 data for Bangladesh, showed that annual mean maximum temperature will increase by $0.40^{\circ} \mathrm{C}$ and $0.73^{\circ} \mathrm{C}$ by the years 2050 and 2100 respectively. The mean tidal level at Hiron Point, Char Changa and Cox's Bazar are showing an increase of $4.0 \mathrm{~mm}$ year $^{-1}, 6.0 \mathrm{~mm}$ year $^{-1}$ and $7.8 \mathrm{~mm}$ year $^{-1}$ respectively, which is much higher than the global rate. An increasing tendency in Sea Level Rise (SLR) from west to east along the coast has also been reported (Table 1). In recent years, a new study by Rahman et al. (2011) also reported the similar increasing trend. In the updated study reveals that, mean annual changes in sea level of $5.5 \mathrm{~mm}$ year $^{-1}$ in the south-west region, $7.04 \mathrm{~mm}_{\text {year }}{ }^{-1}$ in the south-central region, and 5.0 and $7.5 \mathrm{~mm}^{\text {year }}{ }^{-1}$ in the eastern-hill region.

Table 1. Increase of tidal level in three coastal stations Bangladesh coast.

\begin{tabular}{|l|l|l|l|l|l|l|l|}
\hline Tidal Stations & Region & $\begin{array}{l}\text { Latitude } \\
(\mathrm{N})\end{array}$ & $\begin{array}{l}\text { Longitude } \\
(\mathrm{E})\end{array}$ & $\begin{array}{l}\text { Trend } \\
(\mathrm{mm} / \mathrm{year})\end{array}$ & 2020 & 2050 & 2100 \\
\hline Hiron Point & Western & $21^{0} 48^{\prime}$ & $89^{0} 28^{\prime}$ & +4.0 & \multirow{2}{*}{$+10 \mathrm{~cm}$} & $+25 \mathrm{~cm}$ & $+1 \mathrm{~m}$ \\
\cline { 1 - 5 } Char Changa & Central & $22^{0} 08^{\prime}$ & $91^{0} 06^{\prime}$ & +6.0 & $4 \%$ & $17.5 \%$ \\
\cline { 1 - 5 } Cox's Bazar & Eastern & $21^{0} 26^{\prime}$ & $91^{0} 59^{\prime}$ & +7.8 & & \\
\hline
\end{tabular}

Source: Adapted from SMRC, 2003.

A World Bank (2000) study suggests that increased salinity alone from a 0.3 meter sea level rise will cause a net reduction of 0.5 million metric tons of rice production. Sea level rise affects coastal agriculture, especially rice production through saline intrusion which degrades soil quality that decrease or inhibit rice production. In the fiscal year (FY) 1997-1998, rice production area was decreased by one per cent compared to the FY 1993-1994, whereas the total rice production was decreased by 26 per cent during the same period (Islam, 2004). Farmers couldn't produce two rice crops during the year so one cropping cycle was used for shrimp cultivation at the same field. As a result, the decrease in rice production is apparently too high with comparison to decrease in cropping area.

Climate change is likely to bring rapid temperature increases in Bangladesh with comparison to the average 
global rate of warming. Winter temperatures will increase more than summer temperatures. The level of winter rainfall is expected to decrease, whilst summer rainfall will increase. Extreme weather events such as heat waves and very high rainfall are likely to become more frequent in this area subsequently the tropical cyclone intensity is expected to rise by $10-20 \%$. The lowest anticipated rise in sea level is $40 \mathrm{~cm}$ by the end of the century (IPCC, 2007).

\section{Effects on Mangrove Forest in Bangladesh}

Coastal zones have suffered a vast loss of mangroves during the last 50 years, mainly due to human activities including intrusion of saline water. Destruction of mangrove ecosystem and bio-diversity, storm surges, afflict fisheries, soil erosion, back water effects, intrusion of salinity (Fig. 1), severe storms and floods (Fig. 2). A $1^{0} \mathrm{C}$ rise in Sea surface temperature (SST) will increase the cyclone intensity by $4 \%, 2^{\circ} \mathrm{C}$ rise by $10 \%$ and $4^{\circ} \mathrm{C}$ rise by $22 \%$ (Emanuel, 1987). It is also reported that, farmer's household, agricultural yields are expected to drop in most tropical and sub- tropical

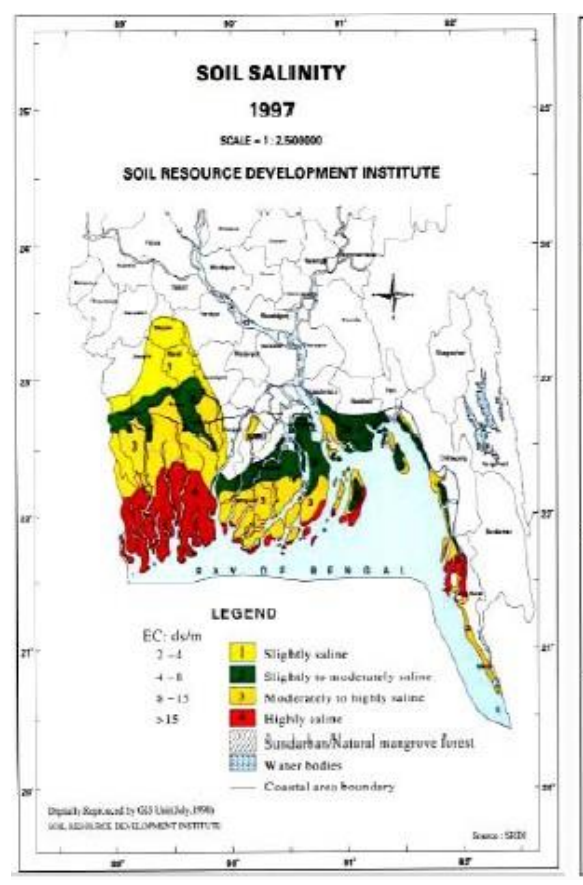

regions, tornado, droughts and desertification will likely to happen. Most of the world's endangered species may extinct ( $25 \%$ mammals and $12 \%$ birds). World's poor human population is vulnerable to climate stress, about 2500, 8000 and $14,000 \mathrm{~km}^{2}$ of land (with a corresponding percentage of $2 \%, 5 \%$ and $10 \%$ with respect to the total land area of the country) will be lost due to Sea level Rise (SLR) of $0.1 \mathrm{~m}, 0.3 \mathrm{~m}$ and $1.0 \mathrm{~m}$ respectively. As a result about one-fourth of the population living in the coastal area will be displaced and subsequently shortage of food grain is likely to be anticipated.

\section{Effects on Coral Island in Bangladesh}

The Climate Change and Sea Lever Rise (CCSLR) are likely to affect the fisheries in Bangladesh including the fishermen and the ecosystem of the St. Martin's coral Island of Bangladesh may also be affected. Increased water temperature and salinity will severely affect many species including reduction of the fresh water fishing area and ultimately the rice production in Bangladesh will be severely affected.

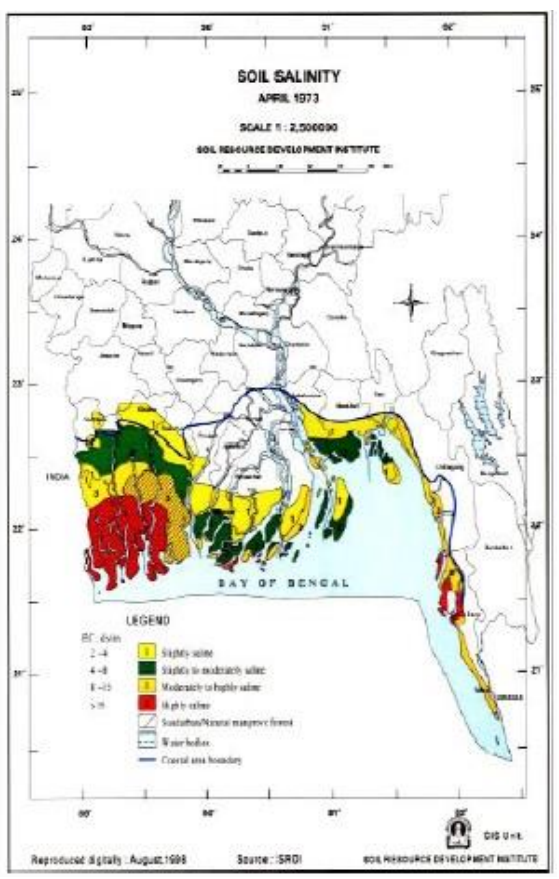

Fig. 3. Comparative Soil Salinity map of Bangladesh (1973-1997) [Source: SRDI, Farmgate, Khamarbari Road, Dhaka1215, Bangladesh]

The ground water aquifers will bear the burden of salinity intrusion subsequently the winter crops in the coastal areas which depend on ground water for irrigation will suffer intensely. In addition due to increase of population the irrigation and drinking water at time will be limiting factor for the urban and rural inhabitants in Bangladesh.

Effect on Food Security in Bangladesh Availability of many local fish species have declined with silting up of river beds. Water shortages and poor water quality have been attributed to the effects of rapid urbanization and industrialization at the South Asia region including Bangladesh. Many parts of Asia have been suffering from a reduction in food production due to reduced water availability, increases in temperature, reduction in rain fall days and increased frequency of the El Nino Southern Oscillation (ENSO). Food productivity is projected to increase slightly at mid-to high latitudes for local mean temperature increases of up to $1^{0}$ to $3^{0} \mathrm{C}$ depending on the crop and then decrease beyond that in some regions (WGII 5.4, SPM, in IPCC, 2007). At lower latitudes, especially is seasonally dry and tropical regions. Crop productivity is projected to decrease for even $1^{0}$ to $2^{0} \mathrm{C}$ local temperature which would increase the risk of hunger (WGII 5.4, SPM, in IPCC, 2007). Globally, the potential for food production is projected to increase with increases in local average temperature over a range of $1^{0}$ to $3^{0} \mathrm{C}$, but above this temperature it 
is projected to be decreased (WGII 5.4, 5.5, SPM in IPCC, 2007).

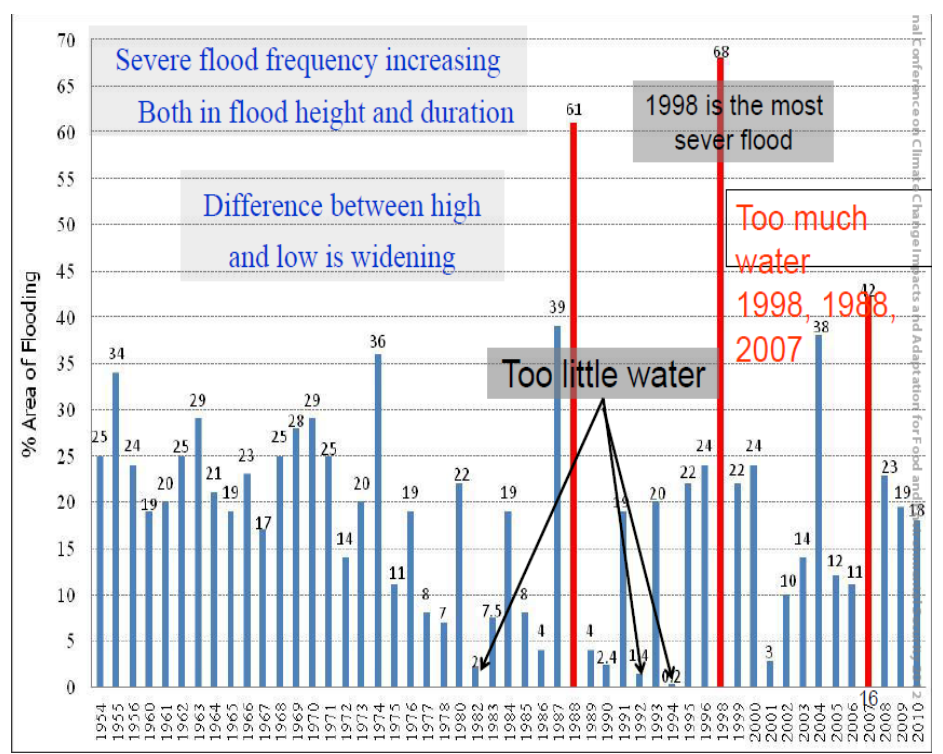

Fig. 4. The Flood frequency and area inundated since 1954 in Bangladesh (Source: BWDB, 2013)

In one experiment using GFDL model that predicted about 17 per cent decline in overall rice production and as high as 61 percent decline in wheat production compared to the baseline situation 1990. The highest impact would be on wheat followed by varieties of Aus crops. CCCM model predicted a significant, but much reduced shortfall in food grain production may likely to be happened (SMRC, 2003).

Increase in $4^{\circ} \mathrm{C}$ temperature would have severe impact on food grain production, especially for wheat production. On the other hand, carbon-dioxide fertilization would facilitate food grain production. Moreover, doubling of atmospheric concentration of $\mathrm{CO}_{2}$ in combination with a similar rise in temperature would result into an overall 20 per cent rise in rice production and 31 per cent decline in wheat production.

It was found that Boro rice would enjoy good harvest under severe climate change scenario. A 60 per cent moisture stress on top of other effects might cause as high as 32 per cent decline in Boro yield, instead of having an overall 20 per cent net increase. It is feared that moisture stress would be more intense during the dry season, which might force the Bangladeshi farmers to reduce the area for Boro cultivation.

In two severe floods, 1974 and 1987, the shortfalls in production were about 0.8 and $1.0 \mathrm{Mt}$, respectively. Under a severe climate change scenario the potential shortfall in rice production could exceed 30 per cent from the trend, while that for wheat and potato could be as high as 50 and 70 per cent, respectively (Karim, 1996). Under a moderate climate change scenario the crop loss due to salinity intrusion could be about 0.2 Mt, which could be increased up to $0.56 \mathrm{Mt}$ under a severe climate change scenario (Habibullah et al., 1998).

Higher levels of temperature and precipitation would aggravate declining condition of the soils. The organic matter content of the topsoil in majority of the areas has already declined below a critical level. The moderately affected areas would also suffer due to impact of climate change. It is likely that a significant part of the moderately affected soils would become more vulnerable due to further decline in organic matter content of the top soils.

However, the higher concentrations of $\mathrm{CO}_{2}$ in the atmosphere would also have some positive effects on the production, as revealed by the modeling exercise. Thereby, some of the adverse effects would be minimized due to $\mathrm{CO}_{2}$ fertilization but that may not be sufficient to reduce vulnerability toward food security. By the year 2030 the population will be 191.1 million (World Bank, 1993; Atiq and Alam, 2003). Therefore, to become self-sufficient in food grain production in year 2030, additional 23.8 Mt would be required.

\section{Remedies and Adaptation}

With a retreating flood, the farmers always find ways to readjust with the cropping calendar and grow alternative crops. Flash-flood occurs only in some designated areas. Recently crop loss due to flash-flood has been successfully minimized by introducing the submergible embankments in the susceptible areas. Both drought and salinity intrusion have considerably higher impacts on crop production.

Unless appropriate anticipatory adaptation measures are considered now, food grain self-sufficiency would not be achieved in future. Food production in Bangladesh is increasing to keep pace with its increasing population, the scenario may change with a view to the adverse impact of climate change collision like flood, sea level rise, drought, saline intrusion, cyclones etc. Government and different development agencies should concentrate their focus on the integrated way and to develop innovative variety so that on growing national food demand can be met through increasing production 
and adaptability against the adverse impact of climate change.

From time-series data it was reported that the impacts of soil salinity would be manifold under the climate change scenarios including estimated crop loss along with permanent unsuitable condition for agricultural practices (Atiq and Alam, 2003). Consequently, the food security of the country would be vulnerable under stressed climatic condition. The study also revealed that, crop loss scenario may be adjusted through substantial improvement by adapting improved management and salt tolerant variety under increased soil salinity in conjunction with the climate change scenarios.

Chatterjee and Huq (2002) reported that, sea level rise and subsequent adaptation can be addressed by changes in policies that lessen pressure on resources, improve management of environmental risks, and enhance adaptive capacity. As most of the population of the coastal communities of Bangladesh is fishermen and farmers, the adaptation options should be emphasized on these two sectors to overcome the problems of the anticipated issues. Nevertheless, changing policy issues are afar the scope of this study. Few appropriate remedies and adaptation measures are described below:

- Changing agricultural methods (Cropping pattern change, "no-tillage" or "low-tillage", etc.)

- Using nitrogen fertilizers more efficiently, organic farming, precision farming, etc.

- Minimize use of hazardous toxic chemicals in crop field

- Expanding forests in different habitats

- Changing lifestyles and rules

- Coping with changing situation

- Reducing emissions including greenhouse gases

- Taking advantage of existing renewable energy technologies

- Technology versus politics and economics.

- Anticipatory adaptation/ adjustment (with new technological innovations) are the development of heatand drought-tolerant, salt-tolerant crop varieties. Rosenzweig and Parry (1994) have grouped the levels of adaptation which are briefly narrated into following ways.

\section{Policy level}

1. changes of policies through bottom up approach up to national level for the betterment of the farmers

2. shifts in plantation date $( \pm 1$ month) in crop calendar,

3. application of effective irrigation water to the crops which are already under irrigation,

4. changes in crop variety to currently available varieties more adapted to the altered climate and soil environment.

5. Invention oriented investment in regional and national agricultural infrastructure

Adaptation through prioritization
1. Appropriate processing and preservation methods for agricultural products require to be adopted.

2. Strengthening of Seed Production and multiplication sector through enhancing quality and quantity of seed input (BADC and private entrepreneurs).

3. Management of farmers own saved seed (usually of poor quality and the sources of inoculums of hazardous pathogens).

4. Management of nutrition depleted soil in an integrated way,

5. Management of Solid Wastes (Non-hazardous) and generation of energy (where appropriate) including bio-fertilizer.

6. Innovation of adequate stress tolerant varieties of crops; BRRI, BARI, BJRI, BINA, DU, BAU, JU, $\mathrm{RU}, \mathrm{CU}, \mathrm{KU}$ and $\mathrm{AEC}$ requires to contribute with specific mandates.

7. Strengthening conservation of Biodiversity using In situ and ex situ conservation strategies.

8. Adaptation and Integration of Agrotechnologies e.g.; LCC, Drum Seeder, Urea Balls, Alley cropping, floating nursery beds, 'mat nursery', drip irrigation and appropriate mulching etc.

9. Development of Aerial agriculture technologies using roof tops in urban areas, use of multi-layer vertical space for production of crop like mushroom where appropriate.

10. Development and dissemination of Agroforestry and Social forestry technologies at rural and semi urban areas where applicable.

11. Proper management of "Haor areas" which remains un-utilized in dry season.

12. Management of agriculture in the flood prone and saline zone (appropriate root crops / tuber crops / flood tolerant verities are essential to be introduced).

13. Regeneration and management of the Sundarban Mangrove forest: Besides natural regeneration, aided manual regeneration may be tried in ecologically critical habitats to reduce the severity of cyclone and tidal surge.

14. Management of pesticides application, preventive measures for POPs and their intrusion into environment and food chain should be monitored through regulatory act.

15. Alternate eco-friendly management of diseases and pests through cultural practices, regulatory measures, biological and physical methods need to be encouraged.

16. Pro-active role of electronic and printing media to educate and building awareness and preparedness among the people.

17. Technology transfer and replication of success stories of innovative farmers, scientists and technologists.

To measure the exact rise in sea level in the coast of the country, sediment supply in the delta and rate of subsidence and uplifting needs to be studied scientifically and elaborately. It was also found that the soil salinity generally increases rapidly in the winter 
months and reaches maximum values in April (Atiq and Alam, 2003).

Present economic growth diminishing the current rice cultivation areas and expanding urban areas. Therefore, sufficient food production is of paramount necessary to meet future national demand which will have to come from smaller areas and diversification of crops are to be made to keep rice prices affordable for poor consumers. Majority of the population reside at rural areas where food security has been ensured through various program. The evenly distribution of food grains among the non-secured area is difficult due to improper transportation facilities.

Bangladesh is falls under remarkably high socioeconomic disparities, household food security requires to be prioritized at national level. Those who are working on food security in Bangladesh needed to be integrated with policy makers towards sustainable development goal.

\section{Conclusions}

The climate change (global warming) issues may result in detrimental effects on food supply and security, especially in developing countries. Even if developing countries adapt to climate change, they will not be able to avoid the problems associated with climate change due to noncompliance of the developed countries to some extent. Furthermore, these harmful outcomes of climate change in developing countries and potentially positive outcomes in developed countries will probably increase the gap in wealth, access to food, and health etc. between rich and poor countries. This will affect the economy of the developing countries with unequal trade-race, resulting in increase of hunger, refugees, displacement, changes of livelihood and deficit of food staff in these developing regions.

Strong sector-wise cooperation's are inevitable to combat the future calamities due to climate change and to protect our successor from the curse of hunger. The following suggestion requires to be adopted for development of long term food security:

implementer

participatory involvement from root level

$\checkmark$ efficient water management for crop cultivation

$\checkmark \quad$ proper marketing of agricultural products

$\checkmark \quad$ enhancement of income and subsequent nutrition level

$\checkmark \quad$ management of postharvest handling including storage facilities

$\checkmark \quad$ introduction of long term soft agricultural loan systems

$\checkmark \quad$ efficient liaison within and among the stakeholders towards development of food security

In addition, educational institutions (public and private universities) and research institutions in association with private sector entrepreneurs and NGOs also have a great importance to stand by the government to combat food security and overall disaster management program.

\section{References}

Ahmed, A. U.; Alam, M. 1999. Development of climate change scenarios with general circulation models. In: Huq, S., Karim, Z., Asaduzzaman, M., Mahtab, F. (Eds.), Vulnerability and Adaptation to Climate Change for Bangladesh. Kluwer Academic Publishers, Dordrecht.

Atiq, R. and Alam, M. 2003. Mainstreaming Adaptation to Climate Change in Least Developed Countries (LDCs) Working Paper: 2. Bangladesh Country Case Study, April 2003. Shell Foundation Sustainable Energy Program.

Bangladesh Bureau of Statistics (BBS). 2002, 2005, 2009, 2010.

Chatterjee, R. and Huq, S. 2002. A Report on the Interregional Conference on Adaptation to Climate Change, Mitigation and Adaptation Strategies for Global Change. 7, pp.403-406.

Department of Agricultural Extension. 2014. Ambia, G. M. 2014, Food Production Situation. Website: www.Icgbanglsdesh.org/Agriculture/Presentation $\backslash 20$ 14\Food Production Situation-DAE.pdf.

Emanuel, K. A. 1987. The dependence of hurricane intensity. Nature, 329: 483-485, Clim. Res., 12: 109-116.

Grain and Feed Annual Bangladesh. 2013. GAIN Report Number: BG30043/28/20132013.

Gregory, P. J. and Ingram, J. S. I. 2000. Global change and food and forest production: future scientific challenges. Agric. Ecosyst. Environ., 82: 3-14.

Habibullah, M.; Ahmed, A. U. and Karim, Z. 1998. Assessment of Food grain Production Loss Due to Climate Induced Soil Salinity: A Case Study, in Vulnerability and Adaptation to Climate Change for Bangladesh, S. Huq, Z. Karim, M. Asaduzzaman and F. Mahtab (Eds.), Kluwer Academic Publishers, Dordrecht, The Netherlands, 1998. pp. 51-66.

Inter-Governmental Panel for Climate Change (IPCC). 2000. ISBN: 92-9169-113-5. Special Report on Emission Scenarios (SRES) 2000.

IPCC. 2007. Climate Change 2007: Impacts, Adaptation and Vulnerability. Contribution of Working Group II to the Fourth Assessment Report of the Intergovernmental Panel on Climate Change, M.L. Parry, O.F. Canziani, J. P. Palutik of, P.J. van der Linden and C.E. Hanson, Eds., Cambridge University Press, Cambridge, UK, 976 p.

Islam, M. S. and Haque, M. 2004. The mangrove-based coastal and near shore fisheries of Bangladesh: ecology, exploitation and management, Reviews in Fish Biology and Fisheries, 14. pp.153-180.

Karim, Z.; Hussain, S. G. and Ahmed, M. 1996. Assessing impacts of climate variations on food grain production in Bangladesh. Water, Air, and Soil Pollution, 92: 53-62.

Karmakar, S. and Shrestha, M. L. 2000. Recent climate change in Bangladesh, SMRC No. 4, SMRC, Dhaka. 
Kothari, C. R. 1992. Research Methodology, Methods and Techniques, $2^{\text {nd }}$ Edition. Willey Eastern Limited, New Delhi 110002.

Naki S. A. 1987. Instruction of Assessment of Socioeconomic Survey. ( $1^{\text {st }}$ Edition), Mohiuddin Ahmed, The University Press Limited, Red Cross Building, 114 Motijheel, Commercial Area, Sanghshaptak Publisher, 19 Sheikh Shaheb Bazar Dhaka, Bangladesh.

Parry, M. 2001. Millions at risk: defining critical climate change threats and targets. Global Environ. Change, 11: 181-183. (doi: 10.1016/S09593780(01)00011-5.)

Rahman, M. M. and Ahsan M. 2001. Salinity Constrains and Agricultural Productivity. Using Geospatial Techniques on Agricultural Landuse: a study on Shyamnagar Upazila, Satkhira Journal of Agriculture and Environment for International Development - JAEID - 2012, 106 (2) 168 in Coastal Saline area of Bangladesh", Journal of Soil Resources in Bangladesh: Assessment and utilization, pp. 1-14.
Rahman, R.; Khan, M. F.; Nishat, B.; Mukherjee, N. and Ahmed, S. 2011. Indicators to Assess Impacts on Hydro-Meteorology. Dhaka: International Union for Conservation of Nature.

Rosenzweig, C. and Parry, M. L. 1994. Potential impact of climate change on world food supply. Nature, 367: 133-138.

SMRC, 2003. The Vulnerability Assessment of the SAARC Coastal Region due to Sea Level Rise: Bangladesh Case, SMRC-No.3, SMRC Publication, Dhaka, Bangladesh.

Soil Resources Development Institute (SRDI). 2010. Land and Soil Resource Utilization Guide (Upazila Nirdeshika, in Bengali): 398 of Shyamnagar Upazila, Satkhira district SRDI 2010. Soil Salinity Report 2010 of Bangladesh, Soil Resources Development Institute, Dhaka, Bangladesh.

World Bank. 2000. Bangladesh: Climate Change \& Sustainable Development. Report No. 21104 BD, Dhaka. 